\title{
Trocar Device
}

National Cancer Institute

\section{Source}

National Cancer Institute. Trocar Device. NCI Thesaurus. Code C50327.

A sharp, pointed rod designed to pierce the wall of a body cavity to withdraw fluid or allow placement of a catheter or other device. 